Craige Roberts

May 8, 2001

Appears in the Handbook of Pragmatics, Horn \& Ward (eds.) (2004) Blackwell.

\title{
Context in Dynamic Interpretation
}

\section{Context, Semantics and Pragmatics}

The linguistic sub-fields of semantics and pragmatics are both concerned with the study of meaning. We might say that semantics studies what Grice (1967) (Chapter 5) called the timeless meaning of a linguistic expression $\phi$-the basic meanings of the words in $\phi$ composed as a function of the syntactic structure of $\phi$. Formal semantics, especially since the seminal work of Montague (1973), attempts to develop an empirically adequate theory of semantics for a given language by developing rules which are clear and unambiguous in their application and effect, hence making clear predictions about the possible meanings for a given expression. We assume that words do have basic meanings, and that a given syntactic structure corresponds to a determinate way of composing the meanings of its sub-parts. ${ }^{1}$ Pragmatics, on the other hand, studies utterances of expressions like $\phi$, attempting to explain what someone meant by saying $\phi$ on a particular occasion. It is clear that there is quite often a difference between the timeless meaning of $\phi$ and what someone meant by uttering $\phi$ on a given occasion. It is a truism among native speakers that this difference arises because of the way that the context of utterance influences interpretation. We complain if someone cites what we say out of context, for this may well distort our intended meaning. But what is a context of utterance, and how does it influence interpretation?

For example, Lewis (1979) uses the metaphor of the scoreboard in a language game to characterize in a very general way how context interacts with the content of an utterance. As in a baseball game, there are different facets of the "score"; that is, the information shared by interlocutors is articulated into different types, with different functions in the game. Lewis differentiates, among other things, between the set of presupposed propositions at a point in the conversation, the ranking of comparative salience of entities under discussion at that point, and the current plans of the interlocutors. While the propositional information would play a clear role in satisfying, say, factive presuppositions, the ranked salient entities might play a role in resolving anaphoric reference, and an interlocutor's global plans would plausibly play a role in understanding her local intention to perform a certain type of speech act. Organizing information in this rather abstract way makes it possible to say more clearly exactly what kind of information plays a particular role in interpretation. If we include in the score information about the actual situation of utterance and (at least temporarily) the form and sequence of the utterances themselves, then context so-conceived includes information

\footnotetext{
${ }^{1}$ These are methodological assumptions, not the sort of thing one could prove. While there are fascinating difficulties in maintaining these assumptions, they have proven an excellent point of departure in theory building, and make it possible to understand the productive character of our semantic competence. See Dowty (1979) and Partee (1984) for relevant discussion about these foundational issues.
} 
about the two other notions of context. With this in mind, we will focus here on context as an abstract, structured object.

But what kinds of information does a context include, and how are these organized? In addressing this question I will adopt the strategy suggested for semantics by Lewis (1972): ${ }^{2}$ In order to say what a context of utterance is, we will first ask what a context does in the course of semantic interpretation, and then find something that does that, and does it in a way that comports well with our semantic theory. A pragmatic theory which approaches the rigor and predictive power of formal semantics would presuppose a theory of the linguistic structures (syntactic, morphological, prosodic) of an utterance. And it would include both a well-defined notion of linguistic context, and a specification of how structure and context interact with semantic rules to yield the attested felicity and interpretations for particular utterances. Such a theory would be capable in principle of making clear predictions about the meanings conveyed by utterances in particular contexts.

In the following section we will consider what it is that context does to interact with semantic interpretation. In Section 3 we will consider the influential development within formal semantics of theories of dynamic interpretation, which involve a more sophisticated view of context and its role in interpretation than in earlier work. In Section 4 we will consider how such theories are currently being extended to account for a wider range of pragmatic phenomena. Section 5 presents conclusions.

\section{What Context Does: Felicity and Context Update}

Context interacts with the semantic content of an utterance during the course of interpretation in two fundamental ways: It is crucial in determining the proposition (or question, or command, etc.) which a speaker intended to express by a particular utterance, and it is in turn updated with the information conveyed by each successive utterance. The first role-the context-dependence of interpretation-is most obvious when phenomena like anaphora, ellipsis, and deixis are involved. When these occur in the utterance, its semantic interpretation is essentially incomplete, and the intended truth conditions can only be determined on the basis of contextual clues. These phenomena are all-pervasive in linguistic interpretation. Consider how we interpret tense. In a language like English, past tense is interpreted relative to a (presumed) time of speech, and hence is indexical, while in a language like Korean (see Yoon (1996)) past tense in an embedded clause is interpreted relative to the event time of the main clause, and so is anaphoric.

The phenomenon of context-dependence can be conceived more broadly in terms of felicity. The aptness of an utterance depends on its expressing a proposition which one could take to be reasonable and relevant in the context of utterance. What this means in practice is that we have to look at the context to determine what was expressed, either

\footnotetext{
${ }^{2}$ Lewis (p.173) advises semanticists: "In order to say what a meaning is, we may first ask what a meaning does, and then find something that does that."
} 
because it was inherently incomplete, as with anaphora or ellipsis, or because its prima facie interpretation would appear to be irrelevant or otherwise infelicitous. Felicity in this sense has many reflexes. For example, knowledge of the context of utterance is crucial in figuring out what speech act a speaker intends to perform by the utterance of an imperative like Hand me the rope. Only by considering the relative status of the interlocutors in the situation in question and the information which they share about where the rope is, whether the speaker needs or wants it, and what's to be done with it, can we form a hypothesis about whether this constitutes a request, a command, permission, or advice to the hearer to hand the rope to the speaker. Otherwise, we cannot say what type of obligation the speaker urges the hearer to undertake, and hence, we cannot understand the sense of the imperative.

Another reflex of felicity is the determination of intended reference. This includes anaphora resolution and deixis, but reference problems tied to context are quite often more subtle than these paradigmatic reference problems, and may be encountered in nonpronominals, as well, as illustrated by the following:

Please hand me some lilacs. (inspired by Wagner (2000))

If (1) is uttered in a florist's, we are likely to take some lilacs to refer to the reproductive organs of plants cut for decorative use. But if the addressee is standing by a row of containers filled with silk flowers, with no organic flowers in view, the reference of lilacs will generally be extended to include artificial lilacs. The two kinds of referential problems - anaphora and contextual suitability of reference-are often combined in definite descriptions, as pointed out by Nunberg (1977). We see this in the following discourse inspired by his examples:

(2) Where's the ham sandwich?

(3) He's sitting at table 20.

A definite description is generally taken to presuppose existence of some entity which is unique in satisfying the NP's descriptive content, and moreover it has been argued that this entity is presupposed to be familiar to the interlocutors. ${ }^{3}$ Carrying a presupposition puts a requirement on the context in which the NP can be feliciously uttered. As in other cases involving definite descriptions, (2) will only express a felicitous question where the context entails that there is a unique ham sandwich in the situation under discussion, which is familiar to the interlocutors. ${ }^{4}$ If (2) is uttered in a kitchen, five minutes after one of the interlocutors has prepared a ham sandwich in full view of the other, the ham sandwich will be taken to refer to the one recently prepared. But uttered by a waitress standing at the kitchen door holding a ham sandwich and scanning the house, the reference of the ham sandwich will more likely be shifted to refer to the person who

\footnotetext{
3 The exact character pf the presupposition association with definite descriptions is disputed. See Russell (1905), Heim (1982), Kadmon (1990), Neale (1990), and Roberts (2000) for a range of suggestions, and Abbott (this volume) for general discussion.

${ }^{4}$ See Karttunen (1973), Stalnaker (1974), and Beaver (1997) for extensive discussion of presupposition satisfaction.
} 
ordered the sandwich she's holding. In this context, someone might answer (2) with (3). Since ham sandwiches cannot generally be referred to with masculine pronouns, the familiarity presupposition associated with he will fail unless the meaning of the definite description has been shifted from the more literal denotation to the associated male customer. This would lead the cooperative hearer to make the shift, guaranteeing that the utterance will be felicitous, taken to mean that the person who ordered the ham sandwich is at table 20.

Beyond reference and anaphora, interlocutors look to the context for the resolution of any presuppositions conventionally triggered by lexical items or constructions in an utterance. ${ }^{5}$ Like pronominal anaphora, other sorts of presuppositions are often radically indeterminate, as we see with too:

$$
\text { [Foc I] ordered a ham sandwich, too. }
$$

The presupposition associated with too is determined by searching the context for a proposition just like that expressed by the clause to which it is adjoined except that some other individual is substituted for the focused constituent in that clause. Here, this would be a proposition of the form $x$ ordered a ham sandwich, where $x$ is some individual other than the speaker of (4). In the restaurant context, this might be the proposition that the fellow at table 20 ordered a ham sandwich, a proposition implied by the discourse in (2)(3). Other types of presuppositions, e.g. factives, are more like definite descriptions in having a fairly rich descriptive content. That is, they are sufficiently explicit that if they fail in the context of utterance, what is presupposed can often be reconstructed and hence, if the interlocutor is cooperative, accommodated (in the sense of Lewis (1979)). But when interlocutors cannot resolve such context-dependent elements of an utterance, as in the utterance of (4) out of the blue, it is impossible to determine the proposition that the speaker intended to express. ${ }^{6}$ Hence in the general case, presupposition failure-the inability to resolve the speaker's intended presupposition-results in a lack of truth value for the utterance.

Besides felicity, the other way in which an utterance interacts with the context in which it is uttered in the course of interpretation is by leading to the update of that context. For one thing, when someone utters one of the examples cited above, the fact of that utterance is added to the information contextually available to those who have heard it. Moreover, the content of the utterance itself may make a contribution. After the utterance of (1), unless the addressee rejects the speaker's implicit claim on her cooperation she will be committed to handing him some of the relevant lilacs. Similarly, if those the speaker addresses in asking (2) tacitly agree to accept her question for discussion, that acceptance influences what will constitute felicitous contributions in the succeeding context: Cooperative interlocutors generally attempt to address the questions already posed before changing the subject. Hence, unless (2) is rejected, saying something which

\footnotetext{
55 See Kasper et al. (1999) for extended discussion of this idea, as well as a sketch of its computational implementation, within the framework for pragmatic analysis proposed in Roberts (1996a).

${ }^{6}$ Kripke is said to have made this observation about too $\mathrm{t}$ a workshop on anaphora at Princeton, University, 1990.
} 
doesn't address it would generally be taken as infelicitous or rude, until the question has been answered. And in (3) or (4), if the identity of the intended presupposition is contextually resolved, and the addressees (implicitly) accept its truth, then that proposition is added to their common information. In this way, requests or commands, questions, and assertions can contribute toward satisfying the presuppositions of subsequent utterances, and hence making them felicitous. For example, they may contribute antecedents for anaphora.

I conjecture that all types of pragmatic problems pertain to one or both of the two ways of interacting with context just discussed-contextual felicity or context update. Then any of the phenomena which hinge on felicity would place requirements on the types of information which context should provide in order to determine felicity. For example, deixis involves resolving the presuppositions of the deictic linguistic element-a word, tense, etc.; checking for felicitous use requires that the context provide information about the perceived environment of utterance, in particular, about what is being indicated by the speaker at the time of utterance of the deictic. If we assume that the resolution of deixis is one facet of contextual felicity, then we must assume that the context of interpretation contains not only information conveyed by the linguistic text of the discourse, but also about the physical situation of utterance (see Roberts (to appear)). Another central problem in pragmatic analysis is Gricean conversational implicature. Several authors have argued that such implicatures may be explained as contextual entailments. ${ }^{7}$ For example, if an utterance is prima facie irrelevant, then a meta-presupposition of relevance and reasonable assumptions about the speaker's goals and intentions would lead us to infer that she meant more than she said. Felicity then drives the update of the context with the intended meaning over and above the proposition literally expressed. In order for this type of account to work, context would need to reflect the fact that the interlocutors are committed to something like the Gricean maxims, as well as containing information about the interlocutors' goals and intentions.

In fact, Grice's maxims can be seen as instances of a larger set of conventions-or metapresuppositions-governing the flow of information-exchange in discourse. Just as one's utterances should be relevant to the topic under discussion, clear and unambiguous, and contain an amount of information appropriate to the purposes of the interlocutors' current goals, in the interests of an orderly exchange we observe various conversational turntaking conventions. ${ }^{8}$ These can also be regarded as meta-presuppositions about the wellformedness of the unfolding discourse. Hence, if someone fails to yield the floor at the appropriate point or overlaps with the speech of the interlocutor who has the floor, their contribution is as much in violation of the rules of discourse as a failed presupposition. The consequences of these different types of violation are rather different in character. The failure to resolve a presupposition leaves the interlocutors without an understanding of the proposition expressed, whereas overlapping the speaker is more likely to irritate than to confuse. But in both cases, the problem lies in a failure to make one's

\footnotetext{
7 See McCafferty (1987), Thomason (1990), Welker (1994), and Roberts (1996b) for discussion and illustration.

${ }^{8}$ See the work on conversational analysis for discussion of these principles, e.g. Sacks et al. (1978), and the papers in Atkinson and Heritage (1984).
} 
contributions accord with the evolving structure of the discourse context in such a way as to be maximally cooperative. In order to capture these constraints on felicity, context has to encode, as well, the rules of conversational turn-taking.

Another set of issues in pragmatics concerns matters of prominence and salience in discourse. Topic and Focus have often been argued to revolve around presuppositions about what was under discussion in the previous discourse, so that again, the same notion of felicity can be argued to underlie the acceptability of, say, focus placement in the standard question/answer paradigm, ${ }^{9}$ or topicalization. ${ }^{10}$ We would expect, then, that context would tell us what was under discussion in the relevant respects, in order to determine whether a particular Focus or Topic is felicitous. Similarly, Centering theory attempts to capture what it is that makes certain potential pronominal antecedents more salient than others in a given discourse; and again, it might be said that pronouns carry a presupposition of the salience of their antecedents, with salience a property of the context of utterance. ${ }^{11}$ So the context needs to contain information about what is salient at any given point in the discourse.

Summarizing, what a context seems to do is to store various kinds of information shared in discourse. This information is used to determine felicity in discourse, and in turn it is updated with the contributions of succeeding utterances. Several types of information have been mentioned here. There is propositional information, relevant for factive presuppositions and the like. There is information about both the issues, or questions, and the entities under discussion and about their relative salience, inter alia relevant for presupposition, Focus, Topic, and anaphora resolution. And the context should encode in some form various metaprinciples governing cooperative interchange, including something like the Gricean maxims and the principles of conversational turn-taking. But there is one more constraint on context which has been the subject of considerable interest in the formal semantics community over the past two decades. The information in the discourse context should be encoded so as to capture all the logical constraints on interpretation which have been explored in formal semantics, including entailments, the scope of operators and the potential for binding free pronominals and other variable-like elements, and a requirement on overall logical consistency. It is from the wedding of these logical constraints with the types of pragmatic factors just discussed that theories of dynamic interpretation were born.

\section{Dynamic Theories of Interpretation}

Context in the theories of semanticists who followed the general approach of Montague was captured as a set of indices, or contextual parameters, attached to the interpretive apparatus for a given sentence. These were pointers to specified sorts of contextual

\footnotetext{
9 This approach goes back at least to Jackendoff (1972) in the generative literature, and is explored (under a variety of different theoretical assumptions) in more recent literature, for example in Vallduví (1992), Roberts (1996a), and Schwarzschild (1999).

10 See Ward (1985).

11 See the introduction and papers in Walker et al. (1997).
} 
information, utilitized to feed the relevant information into the process of compositional interpretation which yielded the proposition expressed by the sentence in the specified context. This limited set of indices typically included the world and time of utterance (a way of capturing the facts about the utterance situation, as well as interpreting tenses and utterances of words like now), the speaker and sometimes the addressee (for $I$, we, and you, etc.), the location of the utterance (e.g., for the interpretation of here or local), and a function assigning values to free variables (the logical form counterparts of pronouns and other pro-forms). Additional indices were sometimes posited for elements like indicated objects (for deixis accompanying this and that), or even the relative status of the interlocutors (e.g., for Japanese honorifics or French tu vs. vous) and the level of formality of the discourse. However, it isn't clear that one could in principle specify a finite set of indices of this type which would be adequate to all the types of information relevant for capturing pragmatic influences on interpretation. Moreover, the values given by these indices were arbitrarily selected, without any mechanism for keeping track across a given discourse of what was being talked about and how this might bear on the interpretation of any given utterance in that discourse. And finally, the notion of context in such theories was static, given once and for all for the interpretation of any given sentence, and so leaving no room for the notion that the interpretation of the first part of an utterance might influence the interpretation of the rest.

It was particular problems in anaphora resolution and the interpretation of tenses which inspired the early work on what is now called dynamic interpretation. Heim (1982) and Kamp (1981) focused on the so-called donkey sentences of Geach (1967), illustrated by the following:

(5) If a farmer owns a donkey, he always uses it to plow his fields.

(6) Most farmers that own a donkey use it to plow their fields.

Deceptively simple, these examples are semantically interesting because they show that the way we keep track of information across discourse, including possible anaphoric referents, must be sensitive to the presence of quantificational operators, here always and most, and also that context must be updated sentence-internally. To see this, first note that the indefinite NP antecedent of it in both sentences occurs within a subordinate clause which serves to restrict the domain of a quantificational operator, always or most. For example, in (5) we are not making a claim about just any kind of situation, but only about those in which there is a farmer and a donkey he owns. And in (6), we're making a claim about the proportion of individuals involved in plowing their fields, but the class of individual involved doesn't include all farmers, only those who own a donkey. But if we replace $a$ donkey with a clearly quantificational NP like every donkey, the pronoun it becomes infelicitous, showing that the anaphoric relation in question isn't binding, and must instead be anaphora to some salient entity in prior discourse. But the antecedent in these exmaples, the indefinite $a$ donkey, occurs in the same sentence, showing that if pronouns presuppose a familiar entity from prior discourse context as antecedent, discourse context must be updated in an on-going way even in the course of interpreting a single utterance. Moreover, although these examples show that the indefinite can serve as antecedent of a pronoun under the scope of the operator, the indefinite ceases to be 
accessible to pronouns in subsequent discourse. So, neither (5) nor (6) can be felicitously followed by (7):

(7) It had to be fed extra grain during plowing season last spring.

The central feature of the theories proposed to account for such examples is that utterances are no longer interpreted in isolation. Instead, the meaning of an utterance is treated as a function from contexts (each one a possible context of utterance) to contexts (the contexts resulting from updating the context of utterance with the content of the utterance). Heim called this the utterance's context change potential. This notion of meaning is dynamic in that it changes continuously during interpretation. For example, the interpretation of utterances like (5) and (6) takes place in stages, corresponding in some respects to the two-sentence discourse in (8):

a) A farmer owns a donkey.

b) He uses it to plow his fields.

Interpreting (8) in a context $C$, we first update $C$ with the information contributed by the utterance of (8a), as in (9):

Input context, $C$ :

Propositional information shared by the interlocutors, including the proposition that a speaker $S$ is speaking.

A set of familiar entities, the discourse referents.

Output context $C+(8 a)$ :

The propositional information in $C$ plus the proposition that $S$ uttered (8a)

in $C$ and (assuming no one questions $S$ 's trustworthiness) the information that there is a farmer who owns a donkey.

The set of discourse referents in $C$ plus one for the farmer and one for the donkey.

We do much the same in the first stage of interpretation of (5) and (6), so that the initial context is first updated with the information in the subordinate adverbial clause or subject $\mathrm{NP}$ with its relative clause. We interpret (8b) taking the context of utterance to be $C+(8 a)$, the update of $C$ with the information conveyed by (8a); after considering the gender of the pronouns we reasonably take the salient farmer to be the antecedent of he and the salient donkey owned by the farmer to be the antecedent of it. Just so, in the remainder of (5) and (6) we use the entities made salient by the first part to resolve the anaphora. But there is a difference. We can follow (8) with (7). That is, the update of $C$ with (8a) (and (8b) subsequently) is a permanent update. But in (5) and (6), because of the operators, the update pertaining to the donkey is only temporary. Though there is a permanent effect-ruling out the existence of farmers who own a donkey but doesn't use it to plow-there is no particular salient donkey after interpretation, because the indefinite was used under the scope of an operator to allude to the properties of any arbitrary donkey standing in the requisite relation to a farmer. 
Hence, theories of dynamic interpretation treat meanings as functions on context and utilize techniques developed in formal semantics to capture logical constraints on interpretation, including quantifier scoping and entailment. Contexts are considered by some theorists to be representations of the contextual information in question, as in Discourse Representation Theories (Kamp and Reyle (1993)), by others to be more abstract structured information, as in Context Change Semantics (Heim (1982), Heim (1992)) and Dynamic Montague Grammar (Groenendijk and Stokhof (1989)). ${ }^{12}$ Dynamic Montague Grammar puts greater emphasis on the retention of compositionality as a methodological principle in interpretation, while Discourse Representation Theory tends to dismiss compositionality as uninteresting for natural language. And there are significant differences in the proposed treatments of anaphora. ${ }^{13}$ But the general dynamic approach to the treatment of anaphora and several other types of pragmatic phenomena in discourse is now firmly established in the formal semantics tradition.

This approach offers a new dimension to the earlier characterization of an utterance in Bar-Hillel (1971) as a pair of a sentence and a context. On the dynamic view of interpretation, we might consider an utterance to be a pair of a sentence under a linguistic analysis, e.g. its logical form, and an input context, the context just prior to utterance. Given that the logical form is conventionally correlated with a context change potential, this implies as well an output context, i.e. the value of the context change potential given the input context as argument. For example, (the logical form of) (8a) in the context $C$ is an utterance, which results in the updated context $C+(8 a)$ given in (9).

What kinds of information are in the context in a dynamic theory? Heim takes context to be an elaboration of Stalnaker's common ground to include not only the set of propositions that the interlocutors hold in common to be true (each proposition a set of possible worlds), but also a set of discourse referents. A discourse referent is an abstract entity-under-discussion. Such an entity may or may not actually exist-we can talk about hypothetical entities, even non-existent ones-but we keep track of the information about each such entity across discourse. Heim characterizes a discourse referent informally as a file card; technically, it is an index, corresponding to the referential index on the NPs used to refer to this entity in the discourse. Keeping track of discourse referents permits a theory of the interpretation of pronouns and definite NPs like the ham sandwich in which such an NP carries a presupposition of familiarity to the interlocutors; that is, its utterance presupposes that there is a corresponding discourse referent in the input context of interpretation. Indefinites like $a$ donkey are said to carry novelty presuppositions, requiring that in a context of interpretation there be no pre-existing corresponding discourse referent. Heim's context, then, is an abstract notion, a set with two kinds of information. Discourse representations in Discourse Representation Theory contain

\footnotetext{
12 There is a lot of variation even within one general approach. For a very good, accessible introduction to File Change Semantics (Heim (1982)) and Discourse Representation Theory (Kamp (1981),Kamp and Reyle (1993)) and a comparison of the two theories, see Kadmon (2000). For a fairly accessible introduction to a theory close to the Dynamic Montague Grammar of Groenendijk and Stokhof (1990), see Chierchia (1995).

13 Again, see Chierchia (1995) for extended discussion, Roberts (2000) for an alternative approach and references to the extensive literature.
} 
variable-like elements which behave very much like Heim's discourse referents, as well as formulae that play much the same role as Heim's propositional component of the common ground; in the end, the representations contain much the same semantic content by virtue of a model-theoretic interpretation. Differences aside, in both these theories as well as in other subsequent work on dynamic interpretation, apart from discourse referents most contextual information can be characterized, directly or indirectly, in propositional terms, with a proposition viewed as a set of possible worlds (or situations).

Dynamic theories offer a number of advantages over the earlier index-based theories of context. Since most contextual information is basically propositional in the dynamic theories, it is no longer necessary to attempt to characterize that information as a set of indices, with all the awkwardness of attempting to determine just how many indices, and of what character, are required. With no loss of theoretical elegance, there many be any number of different types of proposition in the context, bearing on the interpretation of an utterance in as many different ways. Moreover, the context can contain information about both prior discourse and the actual situation of discourse, and it is this information which plays a central role in constraining the interpretation of any anaphoric or deictic elements which may be used. Heim treats such elements as presuppositional, and in (Heim (1983)) proposes an important extension of Context Change Semantics to include a full theory of utterance presuppositions and of presuppositional felicity in context. In this extension, an utterance presupposition is taken to be a constraint on contexts of utterance. Technically, the context change potential corresponding to the utterance's logical form is undefined for any context of utterance which does not satisfy the presupposition in question. For example, in (4) above, we saw that the adverbial too in conjunction with the prosody of the utterance conventionally triggers the presupposition that someone other than the speaker has ordered a ham sandwich. The utterance is felicitous in the restaurant context because this context resolves the utterance's presupposition; it entails that the fellow at table 20, who is not the speaker, ordered a ham sandwich. In dynamic terms, we say that the utterance meaning, a function over contexts, is defined in this particular context of utterance; we can update this context with (4) to yield a new context. This is what it means to be felicitous in such a theory. In another context $C^{\prime}$ which didn't entail that someone else had ordered a ham sandwich, the (same) presupposition would fail, leading to infelicity; that is, context update would undefined for utterance of (4) in $C^{\prime}$. Thus, dynamic theories of interpretation avoid the arbitrariness and disconnectedness of the earlier, index-based theories; each utterance looks to the preceding context to resolve its presuppositions, and in turn updates that input context with the information contained in the utterance.

We can see that such a theory realizes at least some facets of Lewis (1979)'s metaphoric discourse scoreboard. We have two elements in the score: a set of propositions and a set of familiar entities, the discourse referents; and this information is updated dynamically, as in a baseball scoreboard, with each utterance, or move in the game. But will such a simple scoreboard suffice? The propositional content of this notion of context is wellsuited to help capture logical relations among utterances, including entailments associated with operators and constraints on operator scope of the sort noted in (5) and (6) above. But, among other things, an unordered set of propositions fails to yield any 
insight into the notion of relevance so central in interpretation (Sperber and Wilson (1986)); relevance requires us to differentiate among those propositions more and less relevant to the purposes of the interlocutors at any given time. And although discourse referents are helpful in developing a theory of anaphora resolution, they fail to capture what it is to be salient, and so fall short of a full theory of anaphora. Given all the things that contexts do, some of these enumerated in the previous section, it appears that we need more types of information and/or more structure in our dynamic scoreboard. The score is rather more complicated than we can capture with only propositions and discourse referents.

\section{Intentions in Interpretation}

Recently, several authors have begun to explore how to extend the notion of context developed in theories of dynamic interpretation to enable the characterization of a wider range of pragmatic phenomena. What would such a theory of context have to include to permit us to address all the issues mentioned in Section 2, so that the resulting notion does all that a context should do? In keeping with the strategy of the earlier indexical theories, we could simply start adding additional sets to the two we already have, the propositions in the common ground and the discourse referents. For example, we could add a distinguished subset of the propositions, the topics under discussion; a subset of the discourse referents, the set of salient entities; another set of propositions characterizing Gricean maxims, principles of conversational turn-taking, and other meta-principles guiding discourse; etc. But this seems rather arbitrary, no more illuminating than the old set of indices. We want to know what is in these distinguished sets, how they are related to each other, and how they get updated by any given utterance. In addition, the theory we have sketched so far deals only with one type of mood, indicative, and so only with a very narrow range of types of speech act. We would like to develop a more general theory, designed to deal with interrogatives and imperatives, as well, and with the full range of speech acts. Only then can we hope to have a basic framework within which to conduct pragmatic analysis, incorporating the results of a formal semantic theory.

Many theorists believe that the place to start in developing a more adequate theory of this type is with consideration of the interlocutors' intentions, following the general view of Grice (1989). Grice argued that our understanding of what it is for an agent to mean something depends on the prior recognition of certain types of intentions. Roughly, we only take a speaker to mean $\varphi$ if we take her to intend that we recognize that she means to convey $\varphi$ and to do so on the basis of her utterance. If this seems obvious, so much the better. Contrast meaning something with spilling the beans: ${ }^{14}$ We cannot inadvertently mean $\varphi$, but we can certainly inadvertently spill the beans with the same informative outcome. This intentional theory of communication is supported by recent work in experimental psychology and psycholinguistics, which strongly suggests that recognition and tracking of interlocutors' intentions is crucial to how babies learn the meanings of

\footnotetext{
${ }^{14}$ For non-native speakers of English: spill the beans is an English idiom meaning something like 'confess
} or betray'. 
their first words. ${ }^{15}$ Reflection reveals that Grice's notion of mutually recognized intention depends on the assumption that interlocutors keep track of each others' intentions and assumptions, that is that they maintain something like a common ground. As will be briefly illustrated here, assuming that relations over intentions are the central organizing features of discourse permits us to give a conceptually simple and cohesive notion of context, which does what it needs to do to facilitate interpretation and characterize infelicity in discourse.

The notion that goals and intentions are the central organizing factors in discourse was developed within artificial intelligence in Planning Theory. Grosz and Sidner (1986) argue that what they call the Intentional Structure of Discourse is central in this way in discourse, and Thomason (1990) argued that recognizing the role of such intentions is central in the development of a theory of pragmatics. ${ }^{16}$ Following Stalnaker (1979), I assume that the primary goal of discourse is communal inquiry - the intention to discover with our other interlocutors "the way things are", i.e. to share information about our world. Drawing on Stalnaker's notion of the common ground (the set of propositions which the interlocutors in a discourse behave as if they all hold to be true, with a proposition realized technically as a set of possible worlds) and the related context set (the intersection of the common ground, the set of worlds where all the propositions in the common ground are true), we can say that our goal is to reduce the context set to a singleton set, the actual world. The linguistic counterpart of an inquiry is a question. Hence, we might take questions to be the formal objects which reflect interlocutors' intentions in conducting discourse. In that vein, Ginzburg (1996b) and Roberts (1996a) propose that interlocutors' discourse goals and intentions be encoded as the set of questions under discussion in the discourse, expanding the information in the discourse context to include a partially ordered set of such questions, as well as the propositions in the interlocutors' common ground.

To understand how goals and intentions fit into the context of discourse, let us pursue Lewis' metaphor of the discourse context as a scoreboard, and consider the character of the corresponding language game. ${ }^{17}$ The principal elements of a game are its goal(s), the rules which players abide by, the moves they may make towards achieving the goals, and the strategies they may pursue in making their moves, the last generally constrained by the first three and, above all, by rational considerations. The goal of discourse is to conduct inquiry by answering the questions under discussion. There are two types of

\footnotetext{
15 See Bloom (2000), especially Chapter Three, for extensive discussion of this idea, with review of the relevant experimental literature. Note that this notion is not incompatible with the view that there is something like an innate Language Acquisition Device, e.g. for phonology and syntax. Even with such an innate ability to acquire linguistic structures when exposed to particular languages, there remains the problem of grasping intended reference and comprehending the conventional extensions of kind-denoting expressions, etc. This is where pragmatics comes in.

16 See also Pollack (1986), Litman and Allen (1990), and much other work in this vein.

17 The development of these ideas here is a modification of that in Roberts (1996a), in turn inspired by Carlson (1983), where they are developed rather differently. Of course, ultimately the comparison of discourse to a game goes back to Wittgenstein (1953), and has been picked up by others, including Lewis (1969) and, of course, Carlson's mentor Hintikka (e.g., Hintikka (1973), Hintikka and Saarinen (1979), and Hintikka (1981)).
} 
rules in the language game, both viewed as constraints on the interlocutors' linguistic behavior: conventional rules (syntactic, compositional semantic, etc.) and conversational rules (e.g., the maxims of Grice (1967)). The latter are not properly linguistic, but are given by rational considerations in view of the goal of the game (e.g., the Maxim of Cooperation follows from the fact that playing the language game is a coordination problem, à la Lewis (1969); Quality from the fact that truth is the ultimate goal; Quantity 1 from the desire to maximize the payoff of a move in view of commitment to the ultimate goal), and of human cognitive limitations (cf. the discussion in Sperber and Wilson (1986) of Relevance and Quantity 2 in this light). ${ }^{18}$ There are two types of moves which players may make, linguistic behaviors which fall under the kinds of acceptable behavior defined by the rules and are classified on the basis of their relationship to the goals of the game: what Carlson calls set-up moves, which are questions, ${ }^{19}$ and what he calls payoff moves, which are assertions, the answers to questions. Note that moves, as intended here, are not speech acts, but the semantic objects which are expressed in speech acts: A speech act is the act of proffering a move. I will return to discuss strategies of inquiry just below.

I assume that there are two aspects to the interpretation of any given move: its presupposed content and its proffered content, corresponding to the two ways that context enters into interpretation discussed in Section 2. The presupposed content of an utterance constrains the types of context in which it may be felicitously uttered. The term proffered is a cover term for what is asserted in an assertion and for the non-presupposed content of questions and commands; hence, this is the content of an utterance which determines how the context of utterance will be updated. Lewis (1969) treats questions as a type of imperative; this seems correct in that a question, if accepted, dictates that the interlocutors choose among the alternatives which it proffers.

Most contemporary semantic analyses regard a question as denoting or determining the set of propositions which are the possible answers (or correct answers, in some theories) to the question; these are the proffered alternatives. If a question is accepted by the interlocutors, this commits them to a common goal, finding the answer; like the commitment to a goal in Planning Theory, this is a particularly strong type of commitment, one which persists until the goal is satisfied or is shown to be unsatisfiable. The accepted question becomes the immediate topic of discussion, i.e. the immediate question under discussion. When interlocutors accept a question, they form an intention to answer it, which intention is entered into the common ground. ${ }^{20}$ If a cooperative interlocutor knows of this intention, she is committed to it, i.e. she herself (ostensibly) has an intention to answer the question. Then Relevance, an organizing principle of

\footnotetext{
${ }^{18}$ Here and below, I capitalize the Gricean notion of Relevance, and the related notion which I will formally define below, to distinguish them from the ordinary English term.

19 and, as we will see below, the sort of semantic object expressible by imperatives, which also establish goals, although of a different type than those established by accepted questions.

${ }^{20}$ This is in distinction to Carlson's epistemic desideratum of a question, which has to do with increasing the knowledge of the questioner, or with the related views of Ginzburg (1996a). On the present view, it is the common ground, not the speaker, that's "informed", and it is mutual-belief-behavior, and not knowledge, that's sought. This permits a generalization over rhetorical questions, quiz questions, etc., which are problems for more solipsistic views of information in discourse.
} 
discourse which supports coherence and hence facilitates the processing and storage of information, will lead her to attempt to answer it as soon as possible after it is asked. Grice's Quantity 1 maxim, in view of the goals of discourse, makes a complete answer preferable to a partial one.

Assertions are, as for Stalnaker, choices among alternatives. If accepted, they are added to the common ground and thereby shrink the context set. In order for discourse to be coherent (obey Relevance), it must be clear what alternatives (corresponding to cells in a partition on the context set) a given assertion selects among. The relevant alternatives are those proffered by the question, or topic, under discussion. That's the sense in which assertions are payoff moves - they choose among the alternatives proffered by a set-up move/question, and in so doing they further the goals of the game. Non-sequiturs are assertions which don't bear on the question under discussion; even though informative in the abstract, they reflect poor strategy and a lack of commitment to the immediate goals of the discourse, i.e. a lack of cooperation. Non-sequiturs also fail to maximize pay-off; good strategists make assertions with a view to optimizing the number of relevant inferences that they will trigger, and it seems reasonable to assume that such inferences are facilitated by the discourse segmentation induced by the plan structure of the discourse (see Grosz and Sidner (1986), Sperber and Wilson (1986), though the latter don't use the term discourse segmentation).

Strategies of inquiry are sequences of moves designed to (at least partially) satisfy the aims of the game, while obeying the game's constraints. A reasonable strategy to answer the questions under discussion, which may themselves be quite difficult, will involve a plan to do this by approaching sub-goals (addressing sub-questions) which are easier to achieve and are logically related to each other in such a way as to facilitate achieving the main goal. We can define an entailment relation on questions, following Groenendijk and Stokhof (1984), p.16: One interrogative $Q_{1}$ entails another $Q_{2}$ iff every proposition that answers $\mathrm{Q}_{1}$ answers $\mathrm{Q}_{2}$ as well. (This presupposes that we're talking about complete answers, for otherwise the entailments can actually go the other way around.) E.g.: What do you like? entails What food do you like?. We might call $\mathrm{Q}_{1}$ in such a relation the superquestion, and any $\mathrm{Q}_{2}$ which it entails a subquestion. On the other hand, if we can answer enough subquestions, we have the answer to the superquestion. And even answering a particular question may have several parts, involving presenting and arguing for complex information. Again, there may be better or worse ways of presenting this complex information in order to maximize its inferrential potential for our interlocutors, and determining how to do so is part of the strategy we develop. Given the ultimate aim of discourse and the rationality of the participants, these types of relations are the principal factors that structure our moves.

Besides the discourse goal of inquiry in its most general sense, we usually have goals in the real world, things we want to achieve quite apart from inquiry, our domain goals. And our domain goals, in the form of deontic priorities, generally direct the type of inquiry which we conduct in conversation. We are, naturally, most likely to inquire first about those matters that directly concern the achievement of our domain goals. Once we've committed ourselves to a given question, i.e. we intend to answer it, then we 
pursue it until and unless it is either answered or it becomes clear that it isn't presently answerable. But the interlocutors' strategy in this pursuit may include the decision to pursue answers to sub-questions, i.e. a series of related questions may realize a strategy to get at the answer to the most general, logically strongest question among them.

Hence, a strategy of inquiry will have a hierarchical structure, based on a set of questions partially ordered by entailment. Relative to each such question in the resulting partial order, we pursue some rhetorical stategy or other to address that question. Things are actually more complex than this, as questions in an actual strategy may be only logically related in view of certain contextual entailments. But this is the basic nature of strategies, and in what follows I will assume that they have this idealized logical structure, relativized to context.

To get a general feeling for the character of strategies of inquiry, consider the following example from Asher and Lascarides (1998a):

a. A: I need to catch the 1:20 to Philadelphia.

b. Where's it leaving from?

c. B: Platform 7.

d. A: Where do I get a ticket?

e. B: From the booth at the far right end of the hall.

Informally, (11) gives the update dynamics of the discourse context in (10). At each stage, the context is a four-tuple, consisting of the set of discourse referents known by the interlocutors; the set of recognized domain goals; the set of questions under discussion (QUD), i.e. the accepted discourse goals; and the common ground (CG) of the interlocutors, a set of propositions. Propositions and questions are represented by material in italics; it should be borne in mind that these are actually sets of possible situations and sets of sets of possible situations, respectively, and not sentences of English or representations of such; that is, propositions and questions are informational entities.

(11) Dynamics of the Context for Discourse (10):

Input context $C$ :

Discourse Referents: empty of relevant entities

Domain Goals: $\quad$ empty

QUD:

empty (nothing under discussion)

CG:

empty except for general world knowledge among strangers, including the information that to catch a train one needs to know where it leaves from and where to get a ticket for it

$C+(10 a)$ :

Discourse Referents: $\{x=1: 20$ train to Philadelphia $\}$

Domain Goals: $\quad$ A $\quad$ catches $\mathrm{x}$ \}

QUD: $\quad<$ how does one catch $x$ ?> 
CG:

general world knowledge among strangers $+\{A$ needs to catch $x$ \}

$(C+(10 a))+(10 b):$

Discourse Referents: $\{\mathrm{x}=1: 20$ train to Philadelphia $\}$

Domain Goals: $\quad\{$ A catches $\mathrm{x}\}$

QUD: $\quad$ how does one catch $x$ ?, where is $x$ leaving from?>

CG: $\quad$ general world knowledge among strangers $+\{A$

needs to catch $x$, A inquired about where $x$ is

leaving from

$((C+(10 a))+(10 b))+(10 c):$

Discourse Referents: $\{\mathrm{x}=1: 20$ train to Philadelphia. $\mathrm{y}=$ platform 7$\}$

Domain Goals: $\quad$ A catches $\mathrm{x}\}$

QUD:

$<$ how does one catch $x$ ? $>$

CG:

general world knowledge among strangers $+\{A$

needs to catch $x$, A inquired about where $x$ is

leaving from, $B$ asserted that $x$ leaves from platform

$7, x$ leaves from platform 7$\}$

$(((C+(10 a))+(10 b))+(10 c))+(10 d):$

Discourse Referents: $\{x=1: 20$ train to Philadelphia. $y=$ platform 7, $\mathrm{z}=$ ticket for $\mathrm{x}\}$

Domain Goals: $\quad\{$ A catches $\mathrm{x}\}$

QUD: $\quad \quad$ how does one catch $x$ ?, where does A get $z$ ?>

CG: $\quad$ general world knowledge among strangers $+\{A$

needs to catch $x$, A inquired about where $x$ is

leaving from, $B$ asserted that $x$ leaves from platform

7, x leaves from platform 7, A inquired about where to get $\mathrm{z}\}$

$((((C+(10 \mathrm{a}))+(10 \mathrm{~b}))+(10 \mathrm{c}))+(10 \mathrm{~d}))+(10 \mathrm{e}):$

Discourse Referents: $\{x=1: 20$ train to Philadelphia. $y=$ platform 7 , $\mathrm{z}=$ ticket for $\mathrm{x}, \mathrm{u}=$ the hall, $\mathrm{w}=$ booth at far right end of $\mathrm{u}\}$

Domain Goals: $\quad$ A A catches $\mathrm{x}$ \}

QUD:

empty

CG:

general world knowledge among strangers $+\{A$

needs to catch $x$, A inquired about where $x$ is leaving from, $B$ asserted that $x$ leaves from platform $7, x$ leaves from platform 7 , A inquired about where to get $\mathrm{z}, B$ asserted that $A$ could get $\mathrm{z}$ at $\mathrm{w}, \mathrm{A}$ can get $\mathrm{z}$ at $w, A$ knows how to catch $x\}$

At the outset, the interlocutors share little relevant information. A's utterance of (10a) is an assertion, and unless B objects, it is added to the CG; the train itself simultaneously becomes a familiar and salient discourse referent. It is also clear from the content of (10a) (via the meaning of need) that it expresses a goal for A, and unless B objects or otherwise shows herself unhelpful, cooperative principles lead to the addition of that goal to the set of domain goals of the interlocutors. Henceforth, in order to be Relevant to the 
established domain goal, subsequent discourse must attempt to further it, directly or indirectly; this is reflected in the addition to the set of questions under discussion QUD of the question of how to catch the train. (10b) poses a question which is Relevant in that it seeks information required to catch the train, hence that it represents a discourse goal that is part of a strategy to achieve the established domain goal. Given world knowledge about how to catch a train, this new question is a sub-question of the question already on the QUD stack, since knowing how to catch the train entails knowing where to get it. Again, unless B objects, the question is added to the stack of questions under discussion. B's reply in (10c) counts as a complete answer to the question at the top of the QUD stack, and so that question is removed from the stack when the answer is added to the CG, along with the discourse referent for platform 7. Once B in (10c) has resolved the first question, A initiates the next phase of his overall strategy to achieve the domain goal, the discourse goal corresponding to the question in (10d). The treatment of this question/answer pair is parallel in treatment to that in $(10 \mathrm{~b}) /(10 \mathrm{c})$. At the end, the information in CG entails knowing how to catch the train, so the first question is also removed from the QUD, and the issues under discussion are resolved.

Not all discourses involve explicit questions under discussion, but all can be shown to address implicit questions, capturing the intuitive notion of topics under discussion. For example, consider examples (12)-(15) from Mann and Thompson (1986), illustrating various types of rhetorical relations in their Rhetorical Structures Theory:
a. I'm hungry
b. Let's go to the Fuji Gardens.

a. We don't want orange juice.

b. We want apple juice.

a. I love to collect classic automobiles.

b. My favorite car is my 1899 Duryea.

(15) a. Go jogging with me this afternoon.

b. You'll be full of energy.

The assertion in (12a) pertains to a particularly important human imperative, and hence suggests a domain goal, satisfying the speaker's hunger. As usual, suggesting a domain goal raises a corresponding topic for conversation-how to satisfy that goal. (12b) then suggests an answer to that implicit question, going to eat at a particular restaurant. Mann \& Thompson give this as an example of the rhetorical relation of Solutionhood, since the second utterance proposes a solution to the problem posed by the first. This characterization is perfectly compatible with the intentional analysis just suggested.

(13) is an example of the rhetorical relation Mann \& Thompson call Contrast. Note that this contrast would be reflected in utterance of this discourse by placing narrow prosodic Focus on the direct object of want in each clause. Roberts (1996a) proposes a general theory of Focus interpretation in which the focal structure of an utterance presupposes the 
type of question it may address. ${ }^{21}$ Here, the narrow focus on each utterance would presuppose that they address the question of what the speaker and other individual(s) want. If that (probably implicit) question weren't Relevant in the preceding discourse, then utterance of (13) would be infelicitous, as in reply to Where are you two going today?. While it seems correct to characterize this pair of utterances as standing in contrast, by itself this fails to predict the kinds of contexts in which they would be felicitously uttered. But by looking at the discourse fragment with a view to the presupposed question under discussion, we capture both the contrast and felicity.

(14) illustrates the rhetorical relation Mann \& Thompson call Elaboration/set-member. Again, there is no explicit question under discussion in this discourse fragment. But these utterances would be relevant to a question such as What are your hobbies?, or the like. If that were the question under discussion, (14a) would be a (possibly only partial) answer. The elaboration in (14b) would be warranted on the assumption by the speaker that the question was part of a larger strategy to find out what the speaker is like, what he likes and dislikes, etc. If this were the case, then (14b) would be more helpful than the direct answer in (14a) alone, and in keeping with Planning theory generally, a cooperative interlocutor attempts to get at what the query is really after, rather than offering only the information literally requested.

(15) is of interest because the first utterance is an imperative, rather than a question or assertion. Imperatives propose a domain goal to the addressee, that of bringing it about that the proposition expressed by the corresponding indicative with the addressee as subject is true. So (15a) proposes that the addressee make it true that she jogs with the speaker on the afternoon in question. Whether or not the addressee accepts the proposed goal corresponding to an imperative depends on many things, including the relative power of speaker and addressee, degree of cooperativeness, reasonableness of the request, etc. In a situation in which the speaker has little power to force the adoption of the goal, she may attempt to motivate the addressee to accept it by giving reasons why its adoption and achievement are desirable for the addressee, i.e., by addressing the potential question Why should I?. (15b) is relevant to (15a) by virtue of addressing this question of why the addressee should adopt the goal suggested by (15a). This understanding is triggered by the need both to determine the Relevance of (15b) and to resolve the presupposition of a reference time for interpretation of the future tense: If the addressee does accept the proposal and go jogging, 'after you do, you'll be full of energy'. This account in terms of Relevance and questions under discussion is compatible with Mann \& Thompson's characterization of this discourse fragment as illustrating the Rhetorical relation of Motivation. And their rhetorical relations more generally can be seen as types of strategies for pursuing goals in discourse.

Hence, Relevance, Focus and other presuppositions can be used to retrieve questions under discussion which are only implicit, never explicitly asked. It illustrates a prevalent feature of the language gameplan, which is modelled more abstractly in Planning Theory

21 See Roberts (1998b) for application of the theory to the comparative analysis of Hungarian and English, Kadmon (2000) for comparison of this general approach to Focus with others in the contemporary literature. 
via Plan Inferencing Rules that permit us to infer interlocutors' plans from other information in the common ground plus what is actually said. Similarly, sometimes answers which are obviously entailed in a given context are not explicitly uttered, but are nonetheless entered into the common ground. These cases involve accommodation, in the sense of Lewis (1979), and are quite normal in discourse: If it is clear that an interlocutor presupposes a question or assertion $\phi$ which is not yet commonly agreed upon, then if the interlocutors have no objection they behave as if the common ground contained $\phi$ all along. Hence, the notion of a move in a discourse game is essentially semantic. A question is not necessarily realized by a speech act, but is only a questiondenotation in the technical sense, a set of relevant alternatives which the interlocutors commit themselves to addressing. It tells you what the discourse is "about" at that point in the discourse, and further, if we look at the strategy of questions in which it participates, it tells us where the discourse is going.

Let us summarize the picture of context and its role in the dynamic interpretation of a language game which we have developed to this point. I assume that a linguistic structure is an ordered pair of a syntactic structure (with lexical insertion) and a prosodic structure. The interpretation of such a structure is its context change potential, a function from contexts (the potential contexts of utterance) to contexts (the updated contexts resulting from their utterance). An utterance is then an ordered pair of a linguistic structure and a context of utterance. A context is a scoreboard, a way of keeping track of the various types of information being shared in discourse. Like a scoreboard, it is ideally public. The types of information and the way in which they get updated by the proffering of various types of linguistic structure are constrained by the rules of the language game. Here are the facets of the score we have alluded to so far: ${ }^{22}$

(16) Context in Dynamic Interpretation

At a given point in a discourse, the discourse context is an ordered tuple, with at least the following elements:

- a set of Discourse Referents, intuitively the set of entities under discussion

- a set of sets of Domain Goals, to wit:

- a set of Domain Goals for each of interlocutor, what that person is taken to be resolved to achieve, including goals suggested by imperative moves addressed to that person and subsequently accepted

- a set of common Domain Goals, those which the interlocutors are committed to achieving together

- the set of Moves made up to that point in the discourse, with a total order on them corresponding to the order in which they were proffered

- the set of Questions under discussion in the discourse, the QUD: those interrogative moves which have been accepted by the interlocutors and have not yet been satisfactorily answered. Questions ideally remain in the QUD until either answered or abandoned as practically unanswerable, at which time they are removed. So the QUD is non-monotonic.

\footnotetext{
22 See Roberts (1996a) for a detailed formal proposal.
} 
- the set of propositions reflecting the interlocutors' Common Ground. Ideally, monotonic.

The rules of the language game constrain how different types of linguistic structures update the discourse context, with the following principal effects: ${ }^{23}$

Pragmatics of Questions:

(a) If a question is accepted by the interlocutors in a discourse, then it is added to the set of questions under discussion.

(b) A member of the set of questions under discussion in a discourse is removed from that set iff its answer is entailed by the common ground or it is determined to be unanswerable.

\section{Pragmatics of Requests:}

If a request is accepted by an addressee $i$ in a discourse, the set of $i$ 's goals is updated with the information expressed by the corresponding indicative, with $i$ taken as the denotation of the subject.

\section{Pragmatics of Assertion: (following Stalnaker (1979))}

If an assertion is accepted by the interlocutors in a discourse, it is added to the common ground.

The acceptance of a move of any type in the language game depends on its felicity in the context of utterance. If all of the move's presuppositions (in the extended sense suggest in Section 2) are satisfactorily resolved, and the move is accepted by the interlocutors, this leads to an update of the context in the way specific to that type of move. We can then capture Gricean maxims, rules of turn-taking, and other global constraints on wellformed discourse as meta-presuppositions, required to be satisfied for every move. E.g., consider the following characterization of Relevance: ${ }^{24}$

\footnotetext{
23 There will typically be other effects, as well. For example, if a question is asked, the fact that it is asked is entered into the common ground, whether or not it is accepted, this by virtue of the fact that the asking is a speech act performed in full knowledge of all the interlocutors, and that such (non-linguistic) shared information is also represented in the common ground. And if the question is accepted, then the interpretation of the question and the fact that it was added to the set of questions under discussion at that point also becomes part of the common ground, by virtue of the way that the character of the changing context is continuously reflected in the common ground.

${ }^{24}$ This calls out for comparison with Sperber \& Wilson's (1986) notion of Relevance. A detailed comparison is not possible here, but I will note two significant differences between their notion and that given in (15): First, Sperber \& Wilson's Relevance reflects their reductionist program, since it is intended (so far as I can understand) to play the role of all of the original Gricean conversational maxims. (15) is not reductionist; e.g., it is not intended to account for Quantity implicatures. Second, Sperber \& Wilson do not relativize their notion to the interlocutors' immediate intentions or goals (and in fact, they deny the very possibility of a common ground), so that the maximization of informativeness while minimizing processing cost is calculated absolutely. But the Relevance defined in (15) is, crucially, relativized to the question under discussion by the interlocutors, and hence, given the pragmatic function of questions in information structure, to the interlocutors' goals.
} 
(20) A move $m$ in a discourse game is Relevant to the question under discussion $q$ iff $m$ either introduces a partial answer to $q$ ( $m$ is an assertion) or is part of a strategy to answer $q$ ( $m$ is a question subordinate to $q$ or an imperative whose realization would plausibly help to answer $q$ ).

In keeping with the claim that discourse intentions and the questions which express them structure discourse, we also want to guarantee that all of the assertions in a discourse are at least partial answers to accepted questions, and that in fact each is a (partial) answer to the question under discussion at the time of utterance. This follows from the way that Relevance is defined in (20); cf. the relativization of Grice's Maxim of Relevance to "the purposes of the discussion". Without something along the lines of Relevance, it is hard to see how to predict that a given structure would be infelicitous in a given context. And without intentions and goals, it is hard to see how to define Relevance in a way that makes sense for dynamic interpretation. Adding a set of questions under discussion to the characterization of context gives us a way of capturing Relevance in a linguistically relevant way.

The above suggests that some notion of the intentions of interlocutors in discourse is crucial to capturing Relevance, and hence adequately addressing a number of features of discourse context, felicity, and context update. There are various ways we might imagine extending this approach to handle other types of pragmatic phenomena. For example, one can use the intentional structure represented by the questions under discussion to characterize the set of salient entities at that point in the discourse, as suggested in Grosz and Sidner (1986). ${ }^{25}$ This would involve adding an ordered subset of the set of discourse referents, the salient entities, to the types of information in (16), and modifying the context update rules to manage what was in the set of salient entities at a given time in discourse. And one would certainly want to implement some tactics for plan inferencing, in order to infer speech acts (see the earlier work of Perrault (1990)), and ultimately to draw conversational implicatures, as well.

In addition to exploring such extensions, we might want to explore other ways of characterizing the intentions of interlocutors in discourse and the relationship of these intentions to questions and other sorts of speech act. In a series of recent papers (including Asher and Lascarides (1994, Asher and Lascarides (1998a, Asher and Lascarides (1998b)), Asher and Lascarides have discussed various facets of an ambitious project to model discourse processes within a version of Discourse Representation Theory. While their theory makes prominent use of information about interlocutors' intentions, it also makes crucial and extensive use of rhetorical relations, taken to be primitives of the theory. And their theory does not make the types of connections between intentions and questions, and between rhetorical relations and strategies of inquiry, which were discussed above. Asher \& Lascarides also go well beyond the discussion here to propose certain principles for plan inferencing and to explore their interaction with the process of interpretation. A careful comparison of the two types of theory is beyond the scope of the present paper. However, such a comparison should

\footnotetext{
${ }^{25}$ Roberts (1998a) sketches how this might work in a version of Discourse Representation Theory.
} 
ultimately prove useful in determining the extent to which the various structures and principles in discourse are independent of each other.

\section{Conclusions:}

Developing an adequate characterization of the notion of discourse context is arguably at the heart of a fully adequate, integrated theory of pragmatics. Other notions, including presuppositional relations, rhetorical relations, and other facets of what makes a discourse coherent (Halliday and Hasan (1976)) and felicitous, can arguably best be captured in terms of an appropriately modelled relation between a linguistic expression and its context of utterance. In order to do so, however, it is crucial that we include, among the types of information tracked in context, information about the intentions of the interlocutors and general constraints on how these intentions are related to each other in felicitous discourse. Under these assumptions, the resulting model of context, appropriate rules for the semantic interpretation of particular structures and lexical items (which draw on contextually available information), and a suitable inference engine to generate contextual entailments will together yield a satisfactory theoretical account of what how context comes to influence interpretation.

Of course, in actual discourse interlocutors have to do a lot of guesswork to maintain control of a speaker's assumptions about context and, hence, about how particular utterances will be interpreted. In the theory of Hobbs et al. (1993), the fact that we must guess at the assumed context is captured by characterizing actual on-line interpretation in terms of abduction, a process whereby one figures out what the speaker must have assumed the context to be in order for her utterance to denote a true proposition. ${ }^{26}$ Hobb's theory is perfectly compatible with the claim made here that in the ideal discourse pragmatic enrichments of the timeless meaning of an utterance are, like presuppositions, contextual entailments. The theoretical task is to predict the particular interpretations which would be given to particular utterances by ideal hearers who have a full and correct understanding of the context. This is what has to be accounted for from the point of view of linguistic competence. The often incomplete and incorrect character of actual interlocutors' information about contexts of utterance, and the strategies they adopt to compensate for lack of omniscience in this respect-including redundancy ${ }^{27}$ and abductive inference-are of considerable theoretical interest, but are ultimately questions of performance.

One interesting facet of contemporary work on dynamic interpretation and contextdependence is its inter-disciplinary character. Some of the best work in this area is being carried out within computational linguistics and artificial intelligence. ${ }^{28}$ Although one

\footnotetext{
26 Of course, I would add that the proposition must not only be true, but also Relevant.

27 See Walker (1993) for extended discussion of the frequency and function of redundancy in discourse.

28 In addition to work already cited, see the work by Johanna Moore, Richmond Thomason, Karen Lockhaum and their associates, including Moore (1995), Moser and Moore (1996), Thomason and Moore (1995), Thomason et al. (1996), and Lochbaum (1993). Grosz (1997) presents a useful overview of the
} 
reason for this is undoubtedly the heightened commercial interest in creating natural language systems which are more pragmatically sophisticated, another stems from the nature of pragmatics itself. Pragmatics studies phenomena which are at the edge of linguistics proper, the outcome of the interaction between purely linguistic structures (syntactic, phonological, etc.) and more general cognitive capacities and attitudes (inference, perception, belief, intentions, and the like). We cannot adequately characterize such interaction without taking into account both sides of the fence. And hence, purely linguistic study of pragmatics will never yield as much insight as study which takes into account non-linguistic factors as well.

field, with extensive references. And Thomason has an excellent bibliography on context available on his website: http://www.eecs.umich.edu/ rthomaso/bibs/context.bib.txt. 


\section{Bibliography:}

Asher, Nicholas, and Lascarides, Alex. 1994. Intentions and information in discourse. Paper presented at 32nd Annual Meeting of the Association of Computational Linguistics, Las Cruces, NM.

Asher, Nicholas, and Lascarides, Alex. 1998a. Questions in dialogue. Linguistics and Philosophy 21:237-309.

Asher, Nicholas, and Lascarides, Alex. 1998b. The semantics and pragmatics of presupposition. Journal of Semantics 15:239-300.

Atkinson, J.M., and Heritage, J. 1984. Structures of Social Action. Cambridge, England: Cambridge University Press.

Bar-Hillel. 1971. Pragmatics of Natural Language. Dordrecht: Reidel.

Barwise, Jon, and Perry, John. 1983. Situations and Attitudes. Cambridge, Mass.: Bradford Books/MIT Press.

Beaver, David. 1997. Presupposition. In Handbook of Logic and Language, eds. J. van Benthem and A. ter Meulen, 939-1008. Amsterdam and Cambridge, MA: Elsevier Science and MIT Press.

Bloom, Paul. 2000. How Children Learn the Meanings of Words. Cambridge, MA: MIT Press/Bradford Books.

Carlson, Lauri. 1983. Dialogue Games: An Approach to Discourse Analysis. Dordrecht: Reidel.

Chierchia, Gennaro. 1995. Dynamics of Meaning: Anaphora, Presupposition, and the Meaning of Grammar. Chicago: University of Chicago Press.

Dowty, David. 1979. Word Meaning and Montague Grammar. Dordrecht: Reidel.

Geach, P. T. 1967. Intentional identity. Journal of Philosophy 64:627-632.

Ginzburg, Jonathan. 1996a. Dynamics and the Semantics of Dialogue. In Language, Logic and Computation, eds. Jerry Seligman and Dag Westerstahl. Stanford, CA: CSLI.

Ginzburg, Jonathan. 1996b. Interrogatives: Questions, facts, and dialogue. In The Handbook of Contemporary Semantic Theory, ed. Shalom Lappin. London: Blackwell.

Grice, H. P. 1967. Logic and Conversation. William James Lectures, Harvard University.

Grice, Paul. 1989. Studies in the Way of Words. Cambridge, MA: Harvard University Press.

Groenendijk, Jeroen, and Stokhof, Martin. 1984. Studies on the Semantics of Questions and the Pragmatics of Answers, University of Amsterdam: Ph.D. dissertation.

Groenendijk, Jeroen, and Stokhof, Martin. 1989. Dynamic Montague Grammar: A first sketch. Amsterdam: ITLI/Department of Philosophy, University of Amsterdam.

Groenendijk, Jeroen, and Stokhof, Martin. 1990. Dynamic Montague Grammar. In Papers from the Second Symposium on Logic and Language, eds. L. Kálman and L. Pólos, 3-48. Budapest: Adakémiai Kiadó.

Grosz, Barbara, and Sidner, Candace. 1986. Attention, intentions, and the structure of discourse. Computational Linguistics 12:175-204.

Grosz, Barbara. 1997. Discourse and dialogue. In Survey of the State of the Art in Human Language Technology, eds. Hans Uszkoreit, Annie Zaenen and Victor Zue. Cambridge, England: Cambridge University Press. 
Halliday, M. A. K., and Hasan, R. 1976. Cohesion in English. London: Longman.

Heim, Irene. 1982. The Semantics of Definite and Indefinite Noun Phrases, University of Massachusetts at Amherst: Ph.D. dissertation.

Heim, Irene. 1983. On the projection problem for presuppositions. Paper presented at Second Annual West Coast Conference on Formal Linguistics.

Heim, Irene. 1992. Presupposition projection and the semantics of attitude verbs. Journal of Semantics 9:183-221.

Hintikka, Jaakko. 1973. Logic, Language-Games, and Information. Oxford: Clarendon Press.

Hintikka, Jaakko, and Saarinen, Esa. 1979. Information-seeking dialogues: Some of their logical properties. Studia Logica 32:355-363.

Hintikka, Jaakko. 1981. On the logic of an interrogative model of scientific inquiry. Synthese 47:69-83.

Hobbs, Jerry R., Stickel, Mark E., Appelt, Douglas E., and Martin, Paul. 1993. Interpretation as abduction. Artificial Intelligence 63:69-142.

Jackendoff, Ray. 1972. Semantic Interpretation in Generative Grammar. $\square \square$. Cambridge, MA: MIT Press.

Kadmon, Nirit. 1990. Uniqueness. Linguistics and Philosophy 13:273-324.

Kadmon, Nirit. 2000. Formal Pragmatics: Semantics, Pragmatics, Presupposition, and Focus. Oxford: Blackwell.

Kamp, Hans. 1981. A theory of truth and semantic representation. In Formal Methods in the Study of Language, eds. Jeroen Groenendijk, Theo M. V. Janssen and Martin Stokhof. Amsterdam: Mathematische Centrum.

Kamp, Hans, and Reyle, Uwe. 1993. From Discourse to Logic: An introduction to modeltheoretic semantics of natural language, formal logic and Discourse Representation Theory. Dordrecht: Kluwer.

Karttunen, Lauri. 1973. Presuppositions of compound sentences. Linguistic Inquiry 4:169-193.

Kasper, Robert T., Roberts, Craige, and Davis, Paul C. 1999. An integrated approach to reference and presupposition resolution. Paper presented at Association for Computational Linguistics 1999 Annual Meeting, Workshop on the Relationship between Discourse/Dialogue Structure and Reference, University of Delaware.

Lewis, David. 1969. Convention: A Philosophical Study. Cambridge, MA: Harvard University Press.

Lewis, David. 1972. General semantics. In Semantics of Natural Language, eds. D. Davidson and G. Harman, 169-218. Dordrecht: Reidel.

Lewis, David. 1979. Score-keeping in a language game. In Semantics from a Different Point of View, eds. Rainer Bauerle, Urs Egli and Arnim von Stechow. Berlin: Springer.

Litman, Diane, and Allen, James. 1990. Discourse processing and commonsense plans. In Intentions in Communication, eds. Philip R. Cohen, Jerry Morgan and Martha A. Pollack, 365-388. Cambridge, MA: MIT Press.

Lochbaum, Karen. 1993. A Collaborative Planning Approach to Discourse Understanding. Cambridge, MA: Harvard University Center for Research in Computing Technology. 
Mann, William C., and Thompson, Sandra A. 1986. Relational propositions in discourse. Discourse processes 9:57-90.

McCafferty, A. 1987. Reasoning about Implicature, University of Pittsburgh (Pittsburgh, PA): Ph.D. Dissertation.

Montague, Richard. 1973. The proper treatment of quantification in ordinary English. In Approaches to Natural Language, eds. J. Hintikka, J. Moravcsik and P. Suppes. Dordrecht: Reidel.

Moore, Johanna D. 1995. Participating in Explanatory Dialogues: Interpreting and responding to questions in context: ACL-MIT Press Series in Natural Language Processing. Cambridge, MA: MIT Press.

Moser, Megan, and Moore, Johanna D. 1996. Toward a synthesis of two accounts of discourse structure. Computational Linguistics 22:403-419.

Neale, Stephen. 1990. Descriptions. Cambridge, MA: MIT Press (Bradford Books).

Nunberg, Geoffrey D. 1977. The Pragmatics of Reference, City University of New York: Ph.D. dissertation.

Partee, Barbara H. 1984. Compositionality. In Varieties of Formal Semantics, eds. F. Landman and F. Veltman, 281-311. Dordrecht: Foris.

Perrault, C. Raymond. 1990. An application of default logic to speech act theory. In Intentions in Communication, eds. P. Cohen, J. Morgan and M. Pollack. Cambridge, MA: MIT Press.

Pollack, Martha E. 1986. Inferring Domain Plans in Question-Answering, University of Pennsylvania: Ph.D. dissertation.

Roberts, Craige. 1996a. Information Structure: Towards an integrated theory of formal pragmatics. In OSU Working Papers in Linguistics, Volume 49: Papers in Semantics, eds. Jae-Hak Yoon and Andreas Kathol, 91-136: The Ohio State University Department of Linguistics.

Roberts, Craige. 1996b. Information Structure, plans, and implicature. Paper presented at AAAI Symposium on Computational Implicature: Computational Approaches to Interpreting and Generating Conversational Implicature., Stanford University.

Roberts, Craige. 1998a. The place of Centering in a general theory of anaphora resolution. In Centering Theory in Discourse, eds. Marilyn Walker, Aravind Joshi and Ellen Prince, 359-400. Oxford: Oxford University Press.

Roberts, Craige. 1998b. Focus, the flow of information, and universal grammar. In Syntax and Semantic 29: The Limits of Syntax, eds. Peter Culicover and Louise McNally, 109-160. San Diego, CA: Academic Press.

Roberts, Craige. 2000. Uniqueness in definite noun phrases. Ms. The Ohio State University, Columbus, $\mathrm{OH}$.

Roberts, Craige. to appear. Demonstratives as definites. In Information Sharing, eds. Kees van Deemter and Roger Kibble. Stanford, CA: CSLI Press.

Russell, Bertrand. 1905. On denoting. Mind 66:479-493.

Sacks, H., Schegloff, E.A., and Jefferson, G. 1978. A simplest systematics for the organization of turn-taking in conversation. In Studies in the Organization of Conversational Interaction, ed. J. Schenkein, 7-55. New York: Academic Press.

Schwarzschild, Roberts. 1999. GIvenNess, AvoidF and other constraints on the placement of accent. Natural Language Semantics 7:141-177. 
Sperber, Dan, and Wilson, Deirdre. 1986. Relevance: Communication and Cognition. Cambridge, Massachusetts: Harvard University Press.

Stalnaker, Robert. 1974. Pragmatic presuppositions. In Semantics and Philosphy, ed. M. Munitz \& D. Unger, 197-219. New York: New York University Press.

Stalnaker, Robert. 1979. Assertion. In Syntax and Semantics, ed. Peter Cole. New York: Academic Press.

Thomason, Richmond H. 1990. Accommodation, meaning, and implicature: Interdisciplinary foundations for pragmatics. In Intentions in Communication, eds. P. Cohen, J. Morgan and M. Pollack, 325-363. Cambridge, MA: Bradford Books, MIT Press.

Thomason, Richmond H., and Moore, Johanna D. 1995. Discourse context. Paper presented at AAAI Fall Symposium on Formalizing Context, Menlo Park, CA.

Thomason, Richmond H., Hobbs, Jerry R., and Moore, Johanna D. 1996. Communicative Goals. Paper presented at ECAI 96: 12th European Conference on Artificial Intelligence.

Vallduví, Enric. 1992. The Informational Component: Outstanding Dissertations in Linguistics. New York: Garland.

van Dijk, T. 1985. Handbook of Discourse Analysis, Vol. 3: Discourse and Dialogue. London: Academic Press.

Wagner, Peter Alan. 2000. Default Reasoning and Sense Extension: Using hypothetical models to account for polysemy in noun denotations., Linguistics, The Ohio State University: MA.

Walker, Marilyn. 1993. Informational Redundancy and Resource Bounds in Dialogue, University of Pennsylvania: Ph.D.

Walker, Marilyn, Joshi, Aravind, and Prince, Ellen eds. 1997. Centering Theory in Discourse. Oxford: Oxford University Press.

Ward, Gregory. 1985. The Semantics and Pragmatics of Preposing, University of Pennsylvania: Ph.D. dissertation.

Welker, Kate. 1994. Plans in the Common Ground: Toward a generative account of implicature, The Ohio State University: Ph.D. dissertation.

Wittgenstein, L. 1953. Philosophische Untersuchungen/Philosophical Investigations. Oxford: Blackwell.

Yoon, Jae-Hak. 1996. Temporal Adverbials and Aktionsarten in Korean, Linguistics, The Ohio State University: Ph.D. 